\title{
Pharmaco-Resistant Epilepsy Secondary to Occipital Ulegyria
}

Sira Carrasco García de León*, José Javier Bravo-Gómez, María Gudín Rodríguez-Magariños and Amalia Hernández-González

Department of Neurology, University General Hospital of Ciudad Real, Spain

“Corresponding author: Sira Carrasco García de León, Department of Neurology, University General Hospital of Ciudad Real, Spain, Tel: 647867986; E-mail: siracarrasco@hotmail.com

Rec date: Jul 07, 2016; Acc date: Jul 08, 2016; Pub date: Jul 09, 2016

Copyright: (c) 2016 García de León SC, et al. This is an open-access article distributed under the terms of the Creative Commons Attribution License, which permits unrestricted use, distribution, and reproduction in any medium, provided the original author and source are credited.

Citation: León SCG, Bravo-Gómez JJ, Rodríguez-Magariños MG, Hernández-González A (2016) Pharmaco-Resistant Epilepsy Secondary to Occipital Ulegyria . J Neurol Disord 4: i004. doi:10.4172/2329-6895.1000i004

\section{Image Article}

Our patient is a 47-year-old woman. She suffered from prolonged labour at birth which was further complicated by meconial aspiration. Neurological exploration was normal. At age 11, she started experiencing partial complex seizures, consisting on sudden lapses of consciousness with motor automatisms (chewing, sucking, bimanual movements). Afterwards she would stare blankly and remain arreactive for a minute, later showing poscritic confusion. Frequency of these episodes was high, even happening several times a day. 3-Tesla Magnetic Resonance Imaging (MRI) of the brain showed an area of focal atrophy in the left occipital pole with ulegyric pattern criteria (Figure 1). Video-EEG monitoring found no anomalies. Currently she is under treatment with levetiracetam $(3 \mathrm{~g} /$ day $)$, lamotrigine $(500 \mathrm{mg} /$ day) and clonazepam ( $2 \mathrm{mg} /$ day), with partial control of the seizures.

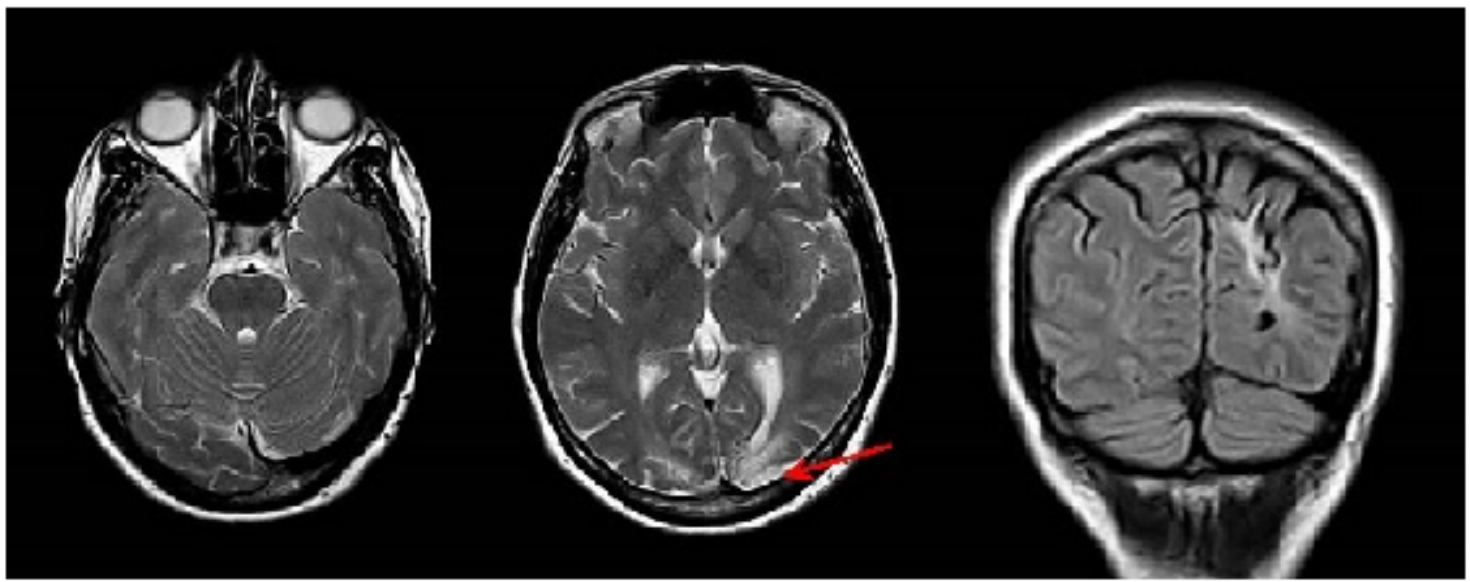

Figure 1: Brain MRI imaging. T2 and coronal FLAIR sequences, showing area of ulegyria involving the left occipital lobe.

Ulegyria is a cortical injury that mostly affects posterior regions $[1,2]$. Its pathophysiology is based on diminished vascular flow. It is an important cause of occipital epilepsy. Seizures are usually limited to the occipital region $[1,2]$. Unlike what has been reported in the literature, our patient did not show localising symptoms, but her seizures' semiology suggested a temporal origin (infrasylvian propagation).

\section{References}

1. Gil-Nagel A, García Morales I, Jiménez Huete A, Alvarez Linera J, Del Barrio A, et al. (2005) Occipital lobe epilepsy secondary to ulegyria. J Neurol 252: 1178-1185

2. Kuchukhidze G, Unterberger I, Dobesberger J, Embacher N, Walser G, et al. (2008) Electroclinical and imaging findings in ulegyria and epilepsy: A study on 25 patients. J Neurol Neurosurg Psychiatry 79: 547-552. 